\title{
La migración de argentinos en la prensa gráfica y los foros de Internet: la construcción diferenciada de colectivos de identificación
}

\author{
Mariana Patricia Busso
}

Resumen: En este artículo se presenta el abordaje teórico empleado para analizar la construcción de colectivos de identificación realizada por la prensa gráfica y por los foros de Internet, entendidos como espacios privilegiados para dar cuenta de los procesos migratorios contemporáneos y, en especial, el fenómeno de la emigración de argentinos del período 2001-2005, estudiado en nuestra tesis doctoral. Reconociendo su importancia como soportes en los que se dota de sentido al proceso migratorio, se presenta una propuesta para su análisis conjunto, reconociendo su importancia en dinámicas específicas de funcionamiento: como formadores de 'lo público' para el caso de los diarios, y como interfaz privilegiada de la escritura personal en línea para los foros, en el marco de una sociedad crecientemente mediatizada.

Palabras-clave: migración; identidades; colectivos; prensa; foros; mediatización.

Abstract: The Argentinean migration in the print media and the internet forums: the distinct construction of collectives of identification - In this paper we develop the theoretical approach to analyze the construction of collectives of identification made by newspapers and Internet forums, as crucial spaces in order to study the contemporary migration processes, especially the phenomenon of the Argentinian recent migration during 2001-2005. To acknowledge their importance as media, in which migration becomes significant, there is a proposal for analyzing both: as formers of newspapers readers, and as a privileged interface of personal and online expressions for the forums, existing in a society increasingly mediatized.

Keywords: migration; identities; collectives; newspapers; forums; mediatization. 


\section{Introducción}

En este artículo nos proponemos plantear las reflexiones teóricas que permitieron el análisis conjunto de la prensa gráfica argentina y de los foros de Internet en el marco de la tesis doctoral "Los emigrantes argentinos y la construcción discursiva de sus identidades: un análisis de la prensa gráfica y de los foros de Internet (2001-2005)", en relación a la construcción de colectivos de identificación realizada en los discursos de ambos soportes.

Los argentinos emigrados en el período 2001-2005 son los protagonistas de un flujo cuantitativamente peculiar en el marco de la historia de la salida de argentinos del país: es a partir de la crisis que estalla en 2001 cuando se produce un impulso inédito en el número de quienes deciden dejar la Argentina, privilegiando como destino europeo a España y a Italia (CALVELO, 2011; OIM, 2012; SICREMI, 2012). Esa emigración de argentinos, que se prolonga hasta 2004-2005 para luego decrecer, es un fenómeno que en el período seleccionado es objeto de una intensa cobertura por la prensa gráfica nacional, mientras que paulatinamente se suma la propia voz de los migrantes utilizando un soporte en boga por aquellos años: los foros en Internet.

El objetivo de este trabajo, entonces, consiste en dar cuenta de la propuesta teórica que en nuestra tesis doctoral nos ha permitido analizar los discursos de los principales diarios de referencia dominante de la Argentina (STEIMBERG y TRAVERSA, 1997) y de los foros de Internet más representativos del período, relativos a la construcción de identidades de los emigrantes argentinos. Concebimos a las identidades que se elaboran en diarios y foros como una producción que se realiza en el discurso: desde la tradición del así llamado giro lingüístico y desde los estudios culturales, se enfatiza la construcción de las identidades a partir del discurso, y a la narración en tanto configuradora de la experiencia humana. En este trabajo, entendemos a la identidad "como el producto efímero de múltiples discursos, siendo invocada "para iluminar la naturaleza inestable, múltiple, fluctuante y fragmentada del 'yo' contemporáneo" (BRUBAKER y COOPER, 2001, p. 9-10), en oposición a conceptos de identidad que enfatizaban su homogeneidad y su posición objetiva en la estructura social.

No se nos escapa, sin embargo, que estamos poniendo en relación discursos que aparecen y se imbrican con dos soportes -la prensa gráfica y los foros de Internet- que adquieren estatutos diferentes al interior del ecosistema mediático: es por ello que partiremos por caracterizar, en el marco de una sociedad que definimos como mediatizada, a los diarios en tanto formadores de opinión, para luego estudiar a los foros como soporte privilegiado de la escritura personal en línea, y entendiendo que se trata de espacios donde se inviste de sentido al desplazamiento migratorio. Finalmente, propondremos un abordaje analítico posible acerca de la construcción de colectivos identificatorios realizada en cada uno de esos soportes. 


\section{Los diarios: la elaboración de colectivos en un medio complejo e ineludible}

Mucho se ha escrito sobre la prensa gráfica: su definición como medio de comunicación y el análisis de sus particularidades ha sido una preocupación temprana, ante la innegable importancia que su aparición y desarrollo comporta para la organización y el funcionamiento de la sociedad. En este trabajo consideramos a los diarios en tanto medio de comunicación, en el sentido que le da Verón a este concepto (más bien sociológico antes que tecnológico): "no solamente un dispositivo tecnológico particular (...) sino la conjunción de un soporte y de un sistema de prácticas de utilización (producción/ reconocimiento)" (VERÓN, 2005, p. 194). Concebimos, además, que se trata de actores que producen símbolos y mensajes que establecen una red de significados operantes en la organización de la sociedad.

Para la investigación, es posible abordar el discurso de/ periódico como una unidad de análisis, sin desconocer la presencia de dispares discursos en el mismo. Siguiendo a Julia de Diego, se trata de enfocarnos en su nivel institucional, cuya unidad de análisis es el discurso del periódico como actor político, en calidad de conjunto, y que circula "como producto de una institución, a la que representa y a la cual suscribe. Así, cada una de las notas posee huellas del proceso de producción de la noticia que imprime la empresa y, como tal, es parte (heterogénea, contradictoria o semejante) de la voz del diario" (DE DIEGO, 2014, p. 12-13); su análisis, entonces, puede dar cuenta de las regularidades discursivas de ese actor en su globalidad.

Entendemos entonces a la prensa gráfica en tanto objeto de conocimiento en sí mismo, que opera como productora de la realidad (VERÓN, 1983), y que puede asumir -entre otros- roles de agente de información, de conductor o formador de opinión, o de partenaire de lectura (STEIMBERG y TRAVERSA, 1997). Asimismo, el carácter central que le ha sido tradicionalmente atribuido a la prensa en el concierto mediático general le adjudica asimismo un lugar privilegiado en la gestión de lo público; siguiendo aquí el desarrollo de Gastón Cingolani, adscribimos a las tesis que sostienen que "en las sociedades mediatizadas lo público se construye en la mediatización" (CINGOLANI, 2013, p. 92; las cursivas son del autor). Los diarios, entonces, operan como una de esas materializaciones de la realidad colectiva y pública producida por los medios. Elaboración realizada en base a la disposición de la propia materialidad y de los recorridos de lectura propuestos: según Cingolani, éstos remiten, a su vez, a un reenvío reticular, que permite hablar de un conjunto de representaciones que colaboran en esa construcción pública.

Así, preguntarnos por la elaboración de identidades a partir de entender a la prensa gráfica desde el punto de vista de la producción del sentido social (CHARAUDEAU, 2003) nos llevará a preguntarnos por las significaciones que allí se construyen sobre 
las representaciones ${ }^{1}$ y los ejes identificatorios a los que adhiere o rechaza un determinado grupo. En efecto, hemos sostenido que son los medios quienes construyen los sentidos que dan forma a lo público; consecuentemente, los diarios serán también esos espacios donde se producen, circulan y se reconocen esos discursos portadores de las representaciones del mundo, de sí mismos y de los otros con los que se designa y se asume un colectivo.

Es central detenernos en este último punto, ya que es desde allí donde se deriva el principal aspecto que nos permite proponer un análisis conjunto de los discursos de diarios y foros. Acordamos con que la creación de colectivos y -consecuentemente- de identidades que pueden adscribirse a éstos, es una de las principales características de la actividad de los medios, estrechamente vinculado a la producción de lo real social por ellos efectuada. Al respecto Verón ha mostrado que ese real producido mediáticamente es múltiple: "hay tantos 'reales' como discursos que se enuncian" (VERÓN, 2001, p. 77) $y$, en esa diferencia, cada actor social puede elegir los imaginarios con los que asocia su creencia. Sin embargo, contemporáneamente, es el medio mismo el que propone las asociaciones posibles, a partir de la permanente elaboración de entidades complejas y nodales para la organización discursiva: justamente, los colectivos que mencionábamos, que identifican tanto el lugar (enunciativo) desde el que se habla, como el lugar (enunciativo) de destinación de ese discurso.

En el marco del estudio de la mediatización de la sociedades contemporáneas, a partir de la propuesta de Eliseo Verón entendemos por colectivos (o colectivos de identificación) a entidades fundamentalmente semióticas, que aglutinan e identifican a una pluralidad de actores², donde "identificación y categorización son operaciones asociadas a estrategias de argumentación, sometidas, por tanto, a reglas de producción de discursos que pueden ser reconstruidas por el análisis" (RETAMOZO y FERNÁNDEZ, 2010, p. 12), y que exigirán de parte del investigador un esfuerzo por reponer y reconocer determinadas estructuras institucionales: sus mecanismos, su naturaleza y sus transformaciones, que operarán a modo de condiciones de producción de esos colectivos. La preocupación de Verón, en este sentido, no se ubica en el plano de la articulación de actores individuales que resulten en experiencias de participación colectiva, sino que lo hace en el nivel de la discursividad, nivel semiótico en el que se manifiestan "los problemas de adecuación entre los grupos sociológicamente determinados (nivel no significante) y los colectivos (las entidades semióticas que identifican a estos grupos, nivel significante)" (RETAMOSO y FERNÁNDEZ, 2010, p. 13). Es allí donde podrá surgir un nosotros, capaz de representar a una suerte de hablante colectivo -aunque no homogéneo-, que no será equivalente a la suma de las fuerzas individuales que lo componen, y los cuales son definidos en

1 Tomamos aquí a la representación en el sentido amplio con que lo hace Charaudeau, quien la define como "resultado de una actividad humana de categorización cognitiva que se refiere a la posición social del sujeto" (2003, p. 21).

2 Como aclaran Retamozo y Fernández (2010), no se trata entonces de sujetos sociológicos definidos por una ubicación diferencial en el mapa social. 
los discursos a través de denominaciones específicas, y a los que se les atribuyen además comportamientos o cualidades determinadas.

Sostenemos entontes en que la prensa, al igual que otras instituciones en la sociedad, es una fuente de generación de esos colectivos ${ }^{3}$. En relación a éstos, cumple una doble función: por un lado, colabora en la producción y en mantener la estabilidad temporal de los colectivos elaborados por otras instituciones de la sociedad; por otra parte, genera sus propios colectivos en el momento en el que los mensajes producidos por sus soportes materiales se han estabilizado y autonomizado en formas institucionales como, justamente, la del diario que los producirá. Este procedimiento, claro está, es fundamentalmente enunciativo: se trata de una operación a través de la cual se construye en el discurso la imagen de a quienes se habla (o de los que se habla); de este modo, podría decirse que la producción de colectivos en el discurso mediático, la elaboración de esas imágenes sobre los destinatarios del discurso, es la accesibilidad posible para la identificación de ese polo de la circulación comunicativa.

La construcción de identidades colectivas, en este sentido, es indisociable de las pertenencias en pugna en esos colectivos semióticos, en las que reconocemos las huellas de procesos sociales en la dimensión significante de esas condiciones productivas. La definición de identidades a las que se adscribirán -o no- esos colectivos, por lo tanto, se vincula con la capacidad de "despertar un sentimiento de pertenencia identitaria generalizada" (VERÓN, 2001, p. 97), definición en la que los medios ocuparán un papel cada vez más central.

En relación a la prensa gráfica y la emigración de argentinos que ha sido objeto de nuestro interés, resulta entonces que los diarios construyen el colectivo emigrantes argentinos, produciendo distintas identidades para éste. Si, a fin de cuentas, la elaboración de un colectivo implica la enunciación de un nosotros que se diferencia de un ellos (VERÓN, 2001), está claro que en la prensa esa construcción será muy distinta a aquélla que podremos analizar en los foros, donde el nosotros del colectivo de los emigrantes argentinos se produce en base a la relación intersubjetiva puesta en acto por la participación de los propios actores en ese espacio.

Para el caso de los diarios, nos encontramos con que esa dimensión del nosotros mediático es la de ese actor institucional a cargo de la producción de una esfera y de una opinión públicas. Sin embargo, ese nosotros del medio da cuenta de un colectivo que no es homologable o, más bien, del que no participan los emigrantes argentinos; de ellos se da cuenta en el discurso de la prensa a través de la enunciación de otro colectivo pero que toma la forma de un ellos de los que se habla, y que ocupa por ende un lugar

3 Al respecto Verón propone que, si la elaboración de colectivos de identificación ha sido un atributo propio del ámbito y de las instituciones y la discursividad política, la crisis de esas instituciones puso en cuestión su capacidad para gestionarlas. A partir de allí, fue el sistema de los medios de comunicación el que comenzó a ser percibido "como el único en condiciones (y perfectamente dispuesto a) controlar la evolución de las identidades colectivas" (Verón, 2013, p. 425), monopolizando la construcción y reconstrucción de los colectivos. 
más bien objetual, más bien de referencia del discurso noticioso. La representación de los emigrantes en esta superficie mediática se realiza entonces a través del mismo mecanismo de producción de ese real, y de ese espacio público: es ese colectivo que elaboran los diarios como un ellos objetual el que aparece tematizado y al que se da forma en esa misma construcción.

Para el caso de Internet, se hace necesario dar cuenta de esa construcción de colectivos entendiendo que, por un lado, la Red ubica e interrelaciona en un mismo soporte físico a medios que antes coexistían en espacios distintos; y que, sumado a ello, se incluyen modalidades de intervención de los sujetos que se consideraban exteriores al entramado mediático, y que aparecen como inseparables de la Red misma: agentes que, ellos mismos, activan "los comentarios inter-individuales, la posibilidad del 'posting', del 'liking'" (CINGOLANI, 2013, p. 110).

\section{Los foros de Internet: la persistencia del interés común}

En nuestro trabajo hemos privilegiado el análisis de la construcción discursiva de las identidades realizada por la prensa gráfica y los foros de Internet. Sobre estos últimos, es menester destacar que, en el recorte temporal propuesto 2001-2005, contaban con un rol preponderante en el ecosistema de la $\mathrm{Web}^{4}$, conformando un espacio relevante para la generación de agrupamientos e identidades, mantenidas a partir de la interacción entre los intervinientes, y en la puesta en común promovida por esa particular interfaz.

En este trabajo consideramos a Internet como un metamedio, según la propuesta de Valdettaro (2007); esto es, como tecnología que alberga en su interior la copresencia de distintos medios y que permite un acceso público a los mensajes que en ellos circulan. Más precisamente, para el caso de los foros allí albergados proponemos que se trata de soportes que la semiótica de los medios ha denominado interfaces interactivas ${ }^{5}$. En este punto, sosteniendo que las interfaces son complejos dispositivos de significación, acordamos con el planteo de Lev Manovich, quien afirma que éstas son capaces de organizar la experiencia humana en relación a los contenidos, a través del desarrollo de una "manera singular de organizar la información, presentarla al usuario, relacionar el tiempo con el espacio y estructurar la experiencia humana en el proceso de acceder a la información" (MANOVICH, 2006, p. 122). Utilizar este andamiaje conceptual para analizar las publicaciones online aparecidas en foros nos obliga a considerar,

4 Desde el punto de vista de la convergencia mediática, podemos apuntar que en los foros identificamos elementos que hoy son habituales en las dinámicas de los actuales sitios de redes sociales: la presencia de comentarios de otros usuarios; la posibilidad de compartir fotos (luego, con la aparición de YouTube en 2005, se podría compartir videos) y la posibilidad de recibir suscripciones a las actualizaciones de las conversaciones a las que se participa; todos ellos elementos que luego serían recuperados y potenciados por otras plataformas.

5 Existe también aquí un intenso debate acerca de los alcances y definiciones de este concepto, así como de sus deudas epistemológicas. Para el caso, se la ha entendido a partir de la mera usabilidad, como una prótesis o instrumento de la interacción online, hasta llegar a identificarla con todo espacio de interacción entre lo real y lo virtual. Para un análisis pormenorizado remitimos a Scolari, 2004. 
por lo tanto, no sólo al tipo de soporte sino también a la actividad de consumo y de producción cooperativa del usuario, en relación e implicada por éste.

Siguiendo a Francisco Yus Ramos, nos encontramos con que en su mecanismo de participación "los foros exigen un conocimiento compartido de los usuarios sobre qué debate se está llevando a cabo y en qué estadio se encuentra la discusión o qué interrelación de discusiones solapadas está produciendo el foro" (YUS RAMOS, 2001, p. 104), cuestión que indica una interactividad dialógica subyacente. Justamente, los foros privilegian -en la lógica de su interacción- el interés o el tópico en común por sobre la puesta en visibilidad del propio perfil o de la propia red de contactos, como sucede con los actuales sitios de redes sociales. Así, mientras que los sitios de redes sociales están estructurados como redes con el individuo al centro de su propia comunidad, "las tempranas comunidades online públicas como Usenet y los foros de discusión abiertos se estructuraban en base a tópicos o según jerarquías temáticas" (BOYD y ELLISON, 2007, p. 10; la traducción del inglés es nuestra), a partir de los cuales se organizaban agrupamientos y redes. Si consideramos por lo tanto que esta interfaz actúa -al igual que los diarios- proponiendo y organizando marcos significativos para la socialización, podemos aventurar que en los foros la emigración funciona como el fuerte vínculo que lleva a la interconexión entre los usuarios.

Precisamente, las intervenciones de los migrantes en foros de Internet no sólo significaron el empleo de un recurso novedoso para la organización de la migración desde el punto de vista de la posibilidad de acceder a un gran acervo de información custodiado en la Red, sino que también brindó la posibilidad de que los migrantes sumaran la propia voz a un espacio donde se apelaba al conocimiento compartido para planificar el viaje del mejor modo posible.

Sin embargo, sería equivocado proponer que es únicamente en ese interés general y experiencial donde radica el carácter relacional de la actividad de los usuarios, ni que solamente en base a él se articula la preocupación por el relato de sí mismo ante esos otros. Justamente, más allá de las características que adquiera la construcción enunciativa de la identidad emigratoria (y del relato de su experiencia) en la enunciación de los propios actores, no debemos perder de vista que estos discursos están interconectados con las prácticas culturales y de consumo que propician estas interfaces online, relacionadas con la conformación de identidades múltiples y móviles.

$\mathrm{Si}$, como sostiene Giovanni Boccia Artieri, en la actualidad los medios son vividos y percibidos como ambientes donde hacer experiencia cotidiana, ya que en ellos se pone en acto la propia realidad, es en ese contexto donde aparece aquello que da el tono a nuestra contemporaneidad: "el (más o menos elevado) reconocimiento de tratar públicamente la propia individualidad, de hacer de la propia experiencia una ocasión de la comunicación en público, con la posibilidad de abrir conversaciones en las que otras vidas se unen a la nuestra" (BOCCIA ARTIERI, 2012, p. 67; la traducción del italiano es nuestra). De este modo, la interrelación entre los usuarios y los medios es constitutiva 
de la significación de las nuevas formas que adopta la sociedad, precisamente a través de la Red y de la representación de la propia experiencia del mundo según las modalidades de reconocimiento y de distanciamiento que posibilitan los medios.

Consideramos entonces que el análisis que proponemos de los foros se engarza con una transformación producida en el ambiente descrito a la hora de construir discursivamente las identidades, y que tiene que ver con ese clima mediático contemporáneo que revaloriza al usuario productor de contenidos, a ese usuario motor de la Red 2.0, y que paulatinamente se ha apropiado de ella hasta convertirla en indisociable del propio estar-en-el-mundo. Es en ese marco que se desarrollan nuevas prácticas y nuevos relatos sobre el sí mismo, compatibles con esas tecnologías; consecuentemente, será la propia experiencia migratoria la que resulta exteriorizada en los discursos presentes en los foros, como parte de esta misma exigencia de visibilidad propia del metamedio Internet.

Los discursos producidos en los foros online, entonces, nos permiten acceder a la vOZ en primera persona de los emigrantes; mediada y posibilitada, por supuesto, por la interfaz tecnológica en la que se pone en acto y que habilita esa gestión del sí mismo online. Este sujeto-migrante se construye a sí mismo, entonces, a través del dispositivo enunciativo, en un discurso al cual accedemos sin atravesar por otras instancias interpretativas previas. Distinto es el caso de los diarios, donde la inclusión de los así llamados testimonios (esto es, la aparición de la palabra de los protagonistas o los involucrados en el hecho noticioso) obedece y responde a las reglas de la lógica de producción de la noticia, en una modalidad de enunciación mediática que incluye a esas voces como parte constitutiva, como insumo de esa discursividad, y no como agente que acceda la construcción noticiosa en modo autónomo.

Sostenemos que en los diarios, precisamente, se construye un migrante-objeto que se produce en calidad de referente noticioso, desde la distancia que instituye la prensa desde su lugar de enunciación. Recordemos aquí que, en tanto medio, los diarios comparten lo que para Charaudeau (2003) es una característica intrínseca: la producción y la distribución de simplificaciones, estereotipos y clichés, obligada si la intención es dirigirse a un público lo más cuantioso -y por ende, lo más heterogéneo- posible. De ello resulta, entonces, que la producción de una determinada imagen del emigrante no se circunscribe ni está dirigida exclusivamente a ese colectivo, sino que interpela a otros, también destinatarios de las notas periodísticas.

\section{A modo de reflexión final: las identidades de los colectivos de emigrantes y los espacios mediatizados}

Proponemos entonces que diarios y foros producen las identidades de los migrantes de acuerdo con las condiciones productivas sociales propias de cada soporte, a la par que organizan particulares matrices de subjetivización. Por lo tanto, el emigrante argentino 
que nos ocupa se trata de un migrante construido por las maquinarias discursivas actuadas en estos soportes. Sin embargo, más allá de reconocer su carácter figurativo, no se nos escapa que ello se enmarca también en ese modo de ser contemporáneos al que se refiriera Leonor Arfuch: un sujeto atravesado por la migrancia, "por la otredad, por la constante inquietud por nuevos destinos" (ARFUCH, 2010, p. 210). También lain Chambers se ha expresado en tal sentido, mostrando que en el mundo contemporáneo la identidad se define en relación al viaje: movimiento que entraña una permanente construcción, en el que esa identidad no es ni fija ni inamovible, y donde juega un rol central el lenguaje, en el sentido de un "medio de construcción cultural en el que nuestros yo [selves] y nuestro propio sentido se constituyen" (CHAMBERS, 1994, p. 42).

La movilidad, precisamente, se ha convertido en una preocupación central para los estudios sociales contemporáneos (URRY, 2002), y no únicamente en el sentido de estudiar las interacciones sociales que se producen en un espacio físico compartido, sino también las formas de sociabilidad que se desarrollan ante la presencia del otro de forma ocasional, imaginada o incluso virtual. Siguiendo con este razonamiento, es pertinente mencionar que Dana Diminescu sostiene que estamos atravesando una nueva era en la historia de las migraciones: la era del migrante conectado. Para esta autora, los migrantes del siglo XXI no pueden ser definidos mediante el concepto de fractura o rompimiento de los espacios y de las fronteras, sino con los de movilidad y de conectividad: "yesterday the motto was: inmigrate and cut your roots; today it would be: circulate and keep in touch" (DIMINESCU, 2008, p. 568). De este modo, la utilización de TIC y el desarrollo de nuevas prácticas comunicativas en Internet habrían producido para los migrantes un cambio en extremo significativo en la gestión y la experiencia de la propia movilidad.

Así, estudiar la construcción de las identidades de los migrantes nos permite también reconocer a diarios y foros como espacios donde se desarrolla el movimiento migratorio, y donde podemos observar cómo se inviste de sentido a ese desplazamiento. Nuestra propuesta, en este sentido, radica en pensar a los medios y a las interfaces digitales como un lugar privilegiado de la movilidad contemporánea, la cual se desarrolla en múltiples espacios que incluyen a esos soportes mediáticos. Así, la producción discursiva de las identidades se relaciona con el modo en que esos soportes pueden convertirse en ámbitos de disputa y de elaboración de tales componentes enunciativos, constitutivos de las migraciones que nos ocupan.

Precisamente, las identidades son convocadas, movilizadas y reconfiguradas en esos espacios mediáticos; creemos, al igual que Myria Georgiou (quien sostiene que los medios "reinforce a sense of belonging but also awareness about links and possibilities for links and connections"; GEORGIOU, 2010, p. 30), que es evidente la estrecha relación que enlaza espacio, identidad y medios, para el caso de las migraciones. Sin embargo, nuestra propuesta avanza en una dirección un tanto distinta de la de esta autora, que privilegia las práciticas de los migrantes en relación al consumo de medios en un entorno 
diaspórico; desde nuestro punto de vista, los propios medios son el espacio mismo en el que se producen las disputas por las identidades en movimiento. Discursos en relación a los cuales, claro está, no excluimos un componente estratégico para su elaboración y consumo por parte de las instituciones mediáticas y de los propios migrantes, más allá de que esa arista no represente un objeto de nuestro estudio.

Proponiendo a los medios como espacios mediáticos, pensamos aquí al espacio siguiendo la propuesta de Doreen Massey, quien muestra que es posible analizarlo yendo más allá de su caracterización geográfica, para pensarlo como "producto de relaciones, una complejidad de redes, vínculos, prácticas, intercambios" (MASSEY, 2004, p. 78) que se suceden en distintas escalas y ámbitos, y en el que se incluyen además las prácticas comunicacionales que dan forma a esos vínculos. Si se nos permite aquí un empleo laxo de este concepto, podemos encontrar que diarios y foros se presentan como espacios de intervención y de yuxtaposición, donde los discursos en ellos producidos dan cuenta de esas movilidades puestas en juego.

Las identidades de los migrantes, entonces, también deben abordarse desde el punto de vista de esa múltiple vinculación: pertenencias no sólo (des)territoriales, sino también construcciones simbólicas producidas simultáneamente en soportes diversos. Analizar las identidades elaboradas en medios y foros entendidos como espacios, entonces, nos habilita a estudiarlas en lo que ellas despliegan como móviles y como puntos de sutura de distintas concepciones (políticas, culturales, institucionales) sobre la actividad migratoria, que se cristalizan y se entrecruzan en su superficie discursiva.

Esto es claro para el caso de los foros: ya para el período que seleccionado (20012005), la utilización de esa forma de las TIC estaba en camino de convertirse en lo que sin lugar a dudas es hoy: una práctica habitual para la preparación del viaje, y una herramienta primordial para la organización y el asentamiento en el lugar elegido ${ }^{6}$. Recordemos que estas interfaces exigen la participación activa del usuario para la producción de contenidos basados en un interés común; yendo más allá, agregamos que ellas adquieren además un rol crucial en la construcción cotidiana de la propia imagen y de la del otro en múltiples modos: entre ellos, permitiendo el contacto y la confrontación entre esas identidades, al interior mismo del espacio habilitado por la interacción online.

Para el caso de los diarios, y remitiéndonos a cuanto ya hemos especificado, reconocemos entonces que se trata de un espacio en el que se busca caracterizar a la práctica migratoria -y a los sujetos que la realizan- en tanto objetos referenciales del acontecimiento noticioso, propuesto en el marco de la elaboración de una agenda pública sobre la emigración. Sostenemos entonces que, a pesar de no contar con

6 En particular, nos referimos aquí a prácticas como el establecimiento de redes de contactos y la planificación remota del viaje, que se ven facilitadas y reelaboradas con el cambio en las modalidades de comunicación impulsado principalmente por la conectividad habilitada por Internet. Y más aún: según Diminescu (2008), con las TIC no sólo se han revolucionado las prácticas migratorias, sino que también lo han hecho el modo en que se experimenta la movilidad y también, implícitamente, la construcción de asentamientos o arraigamientos relacionales. 
las características de inmediatez y simultaneidad que permiten los soportes online, son igualmente determinantes en proponer -con la potencia del modelo broadcasting que le es propio 7 - temáticas y sesgos ineludibles para la gestión colectiva de temáticas de interés común. Pero que, inevitablemente, delimitarán la figura de un migrante atravesado por el posicionamiento del diario en relación al proceso migratorio, aunque con escasas posibilidades de que esos actores que tomaban la decisión de partir encontraran allí la posibilidad de expresar directamente su propia voz, como efectivamente sucederá en los foros.

Mariana Patricia Busso es doctora en Comunicación Social por la Universidad Nacional de Rosario (Argentina). Actualmente es becaria postdoctoral de Conicet (Consejo Nacional de Investigaciones Científicas y Técnicas).

mar_busso@hotmail.com

\section{Referencias}

ARFUCH, L. El espacio biográfico. Dilemas de la subjetividad contemporánea. Buenos Aires: FCE, 2010. BOCCIA ARTIERI, G. Stati di connessione. Milano: Franco Angeli, 2012.

BOYD, D.; ELLISON, N. Social network sites: Definition, history, and scholarship. Journal of ComputerMediated Communication, 13, p. 210-230, 2007.

BRUBAKER, R.; COOPER, F. Más allá de 'identidad'. Apuntes de Investigación del CECyP, n7. Buenos Aires: CECyP, 2001. Disponible en http://www.apuntescecyp.com.ar/index.php/apuntes/issue/view/12

CALVELO, L. Crisis y emigración. La emigración de los argentinos entre 1960 y 2002. Buenos Aires: Misterio del Interior, Dirección Nacional de Población, 2011.

CINGOLANI, G. 2013. El acceso a lo público. Agendas, espaciostiempos mediáticos y transformaciones de los dispositivos. In FERNÁNDEZ, M.; LÓPEZ, M. (eds.). Lo público en el umbral: los espacios y los tiempos, los territorios y los medios. FPyCS: UNLP, 2013. p. 90-114. Disponible en: http://www. cim.unr.edu.ar/publicaciones/1/libros90-114.

CHAMBERS, I. Migración, cultura, identidad. Buenos Aires: Amorrortu, 1994.

CHARAUDEAU, P. El discurso de la información. La construcción del espejo social. Barcelona: Gedisa, 2003.

DE DIEGO, J. El periódico como objeto complejo. Reflexiones teórico-metodológicas. Actas de las XVIII Jornadas de Investigadores en Comunicación, 2014. Disponible en http://redcomunicacion. org/el-periodico-como-objeto-complejo-reflexiones-teorico-metodologicas/

DIMINESCU, D. The connected migrant: an epistemological manifesto. Social Science Information, vol. 47, p. 565-579, 2008.

7 Por broadcasting entendemos la modalidad de comunicación propia de los medios masivos basada en la generación de información por parte de unos pocos emisores, hacia un conjunto múltiple e indeterminado de receptores. 
GEORGIOU, M. Diaspora in the digital era: minorities and media representation. Journal of Ethnopolitics and Minority Issues in Europe, vol. 12, $\mathrm{n}^{\circ}$ 4, p. 80-99, 2013.

MANOVICH, L. El lenguaje de los nuevos medios de comunicación. La imagen en la era digital. Buenos Aires: Paidós, 2006.

MASSEY, D. Lugar, identidad y geografías de la responsabilidad en un mundo en proceso de globalización. Treballs de la Societat Catalana de Geografía, vol. 57, p. 77-84, 2004.

OIM. Perfil migratorio de Argentina, 2012. Disponible en http://www.iom.int/files/live/sites/iom/ files/pbn/docs/Perfil-Migratorio-de-argentina-2012.pdf

RETAMOZO, M.; FERNÁNDEZ, M. Discurso político e identidades políticas: producción, articulación y recepción en las obras de Eliseo Verón y Ernesto Laclau.Cuadernos de $\mathbf{H}$ Ideas, vol 4, n4, pp. 1-22, 2010. Disponible en: http://perio.unlp.edu.ar/ojs/index.php/cps/article/view/1407.

SCOLARI, C. Hacer clic. Hacia una sociosemiótica de las interacciones digitales, Barcelona: Gedisa, 2004.

SICREMI. Segundo informe sobre migración internacional en las Américas, 2012. Disponible en http://www.migracionoea.org/index.php/es/sicremi-es.html

STEIMBERG, O.; TRAVERSA, O. Estilo de época y comunicación mediática. Buenos Aires: Atuel, 1997.

URRY, J. Mobility and Proximity. Sociology, vol. 36, p. 255-274, 2002.

VALDETTARO, S. Medios, actualidad y mediatización. Boletín de la Biblioteca del Congreso de la Nación, $n^{\circ} 123$, p. 51-65, 2007.

VERÓN, E. Construir el acontecimiento. Buenos Aires: Gedisa, 1983.

. El cuerpo de las imágenes. Bogotá: Grupo Editorial Norma, 2001.

. Fragmentos de un tejido. Barcelona: Gedisa, 2005.

. E. La semiosis social, 2. Ideas, momentos, interpretantes, Buenos Aires: Paidós, 2013.

YUS RAMOS, F. Ciberpragmatica. El uso del lenguaje en Internet. Barcelona: Ariel, 2001.

Artigo recebido em maio e aprovado em julho de 2016. 